\title{
$\Lambda$ итература
}

1. Бахтин М. М. Эстетика словесного творчества. М.: Искусство, 1979. 423 с.

2. Василюк Ф. Е. Психология переживания: анализ преодомения критических ситуаций. М.: МГУ, 1984. 200 с.

3. Гессен С. И. Основы педагогики. Введение в прикладную философию / отв. ред. и сост. П. В. Алексеев. М.: Школа-Пресс, 1995. $448 \mathrm{c}$.

4. Даль В. И. Толковый словарь живого великорусского языка: в 4 т. М.: Русский язык, 2002. Т. 4. 688 с.

5. Иванов А. В. Кумьтурная среда современной школы // Педагогика. 2006. № 10. С. 50-55.

6. Коджаспирова Г. М., Коджаспиров А. Ю. Словарь по педагогике. М.: Ростов н/Д: МарТ, 2005. 448 с.

7. Маслоу А. Г. Дальние пределы человеческой психики / пер. с англ. А. М. Татмыбаевой; под ред. Н. Н. Акулиной. СПб.: Издат. группа "Евразия", 1997. 430 с.

8. Морева Н. А. Педагогика среднего профессионального образования: учеб. для студ. высш. учеб. заведений: в 2 т. Т. 2: Теория воспитания / Н. А. Морева. М.: Академия, 2008. 192 с.

9. Ожегов С. И., Шведова Н. Ю. Толковый словарь русского языка. 2-е изд., испр. и доп. М.: АЗЪ, 1994. 928 с.

10. Роджерс К. Р. Взгляд на психотерапию. Становление чемовека: пер. с англ. / общ ред. и предисл. Е. И. Исениной. М.: Прогресс; Универс, 1994. 480 с.

11. Щуркова Н. Е. Воспитание: новый взгляд с позиции культуры. М.: Педагогический поиск, 1997. 39 с.

Удк 37.013 .77

Н. В. Сюзева

\section{ПРОВОКАТИВНЫЕ ПРИЕМЫ ПРИ ФОРМИРОВАНИИ АНТИКОРРУПЦИОННОГО СОЗНАНИЯ}

Аннотаиия. В статье рассматриваются возможность и необходимость применения приема провокации в педагогической деятельности. По мнению автора, этот прием наиболее эффективен, в частности, в ан- 
тикоррупционном воспитании. Проблема всепроникающей коррупции в нашей стране настолько укоренилась, что решить ее известными способами не представцяется реальным. Опыт и социальная теория показывают, что справиться с такой сложной задачей можно Аишь изменяя созна-

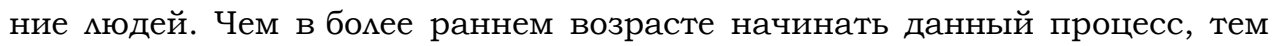
мучше будет его результат.

В концептуальную основу статьи положена провокативная терапия Ф. Фаремли, который использовал методы провокации для мечения больных. Так как коррупция тоже явцяется болезнью - болезнью нации, применение подобных методов в борьбе с ней вполне обоснованно. Провокация позволяет выявить коррупционные установки человека и избавиться от многих из них. Аиквидация проблемных убеждений и установок происходит через доказательство их иррациональности. Приводится последовательность этапов реализации провокативной методики. Описаны некоторые виды педагогических провокаций.

Автор статьи убежден в перспективности педагогики провокаций и в том, что она заслуживает научного обсуждения и дальнейшей разработки.

Ключевые слова: провокативная терапия, манипумяция, антикоррупционное воспитание.

Abstract. The paper is devoted to the necessity of using the provocative methods in pedagogy regarding them as the most effective ones in education focused on fighting the corruption. Both the social theory and human experience demonstrate that we have to change people's consciousness and start it as early as possible in order to overcome corruption.

The author takes the provocative therapy suggested by F. Farelli as the conceptual basis for the research, and considers the corruption phenomenon as the national disease that requires immediate treatment. The provocative methods can be used for identifying the corruption attitudes, emphasizing their irrational nature and getting rid of them. The paper describes the sequence of recommended stages of the above method application and gives some examples of pedagogic provocations.

The author argues that pedagogic provocation is a perspective method stimulating personality development which requires further investigation and discussion. ruption.

Keywords: provocative therapy, manipulation, education fighting cor-

В России в связи с возрастающими темпами развития коррупции на протяжении нескольких последних мет предпринимаются различные меры по борьбе с нею: совершенствуется законодательство, разрабатываются и внедряются стандарты предоставмения государственных услуг, пытаются вести антикоррупцион- 
ную пропаганду представители СМИ. Однако угомовная статистика показывает, что уровень мздоимства ниже не становится коррупционные традиции тщательно поддерживаются и даже охраняются некоторыми, возможно, даже слишком многими должностными Аицами, состоящими на службе в органах государственной вмасти и управления.

С сожалением приходится констатировать, что все действия органов власти и СМИ не дают убедительных положительных результатов. По данным Судебного департамента при Верховном суде РФ, масштабы установленного прямого ущерба от подобного рода преступлений в 2011 г. достигли 26,7 млрд р., тогда как еще в 2009 г. они составляли 15,7 мирд р., что, конечно, тоже огромная, запредельная сумма. Прогрессия связана не только с ростом аппетитов и совершенствованием мовкости коррупционеров, но и с тем, что коррупция стала массовым явлением и настолько поразила общество, что воспринимается почти как норма, как часть культурного наследия целого народа, стереотип его повседневного поведения. "Корммение" государственных служащих их подопечными давно и прочно утвердияось в сознании граждан, вошло в привычку, которую даже кое-кто предлагает узаконить, т. е. сделать правовой нормой. В связи с этим, по мнению ряда экспертов, ст. 575 Гражданского кодекса РФ, которая разрешает чиновникам получение подарков стоимостью до 3000 р., нужно рассматривать как мегальную "мазейку" для коррупционеров.

Свидетельством тому, что коррупция глубоко укоренилась в сознании народа, служит и масса пословиц и поговорок, отра-

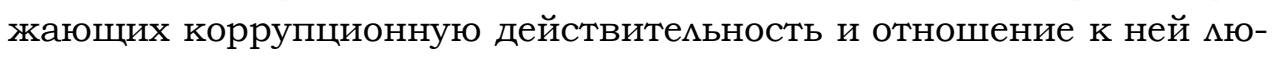
дей, например:

- "Закон, что паутина: шмель проскочит, а муха увязнет";

- "Земля мюбит навоз, мошадь - овес, а воевода - принос";

- "Не подмажешь - не поедешь";

- «Пчелка и та взятку берет»;

- "Скорее дело вершить, коли судью одарить";

- "С кого судья взял, тот и прав стал";

- "Что мне законы, коли судьи знакомы” и др.

Конечно, оправдывать коррупционеров культурными традициями в корне неверно, по крайней мере юридически некорректно: «Непосредственные причины и истоки виновного поведения 
всегда цежат в цичности человека, совершившего преступцение. В противном случае отсутствуют основания вменения в вину и, соответственно, совершенное деяние не может рассматриваться как преступление. Другими словами, никакие внешние обстоятельства не могут явцяться определяющими причинами противоправного деяния, если они не положены одновременно на внутренние детерминанты чемовеческой активности" [6, с. 77].

И все же традиции быта, семьи, культуры играют немаловажную роль в формировании поведения каждого отдельного че-

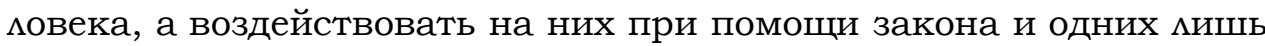
правоохранительных органов довольно сложно, если вообще возможно. Если коррупция стала национальной традицией, то и борьба с ней должна включать в себя в качестве обязательного условия изменение сознания, как общественного, так и индивидуального.

На общественное и индивидуальное сознание оказывают влияние многие социальные институты - государство, церковь и иные религиозные организации, средства массовой информации и, конечно же, система образования. Исторический опыт показывает проблематичность использования и малую эффективность оперативного воздействия на сознание "обычных", традиционных морализаторских педагогических средств. Попытки прямолинейного, авторитарного педагогического влияния, преследующие цель изменения сознания, тем более его социокультурных основ и стереотипов чаще всего приводят к отторжению того, что откровенно навязывают или даже просто предлагают.

Более значимых, существенных результатов можно добиться при тщательно обдуманной тактике, выверенной стратегии, когда педагогическое воздействие осуществцяется тонко и деликатно, в смягченной, сильно опосредованной, завуалированной форме. Процесс преодоления сопротивления мичности воспитанника, перемены в его мировоззрении происходят, как правило, медменно, что требует наличия постоянной, систематической и ситуативнообусловленной обратной связи между педагогом и его подопечным. При этом следует учитывать сложившиеся в среде, к которой принадмежит учащийся, нормы, правила, идеалы, ценности, имеющиеся национально-культурные стереотипы. Дия преодоления данных стереотипов у своих воспитанников педагогу часто необходимо тоже переосмыслить собственные взгляды и представле- 
ния, т. е. потрудиться над изменением своего мичного человеческого и профессионального сознания, по-иному взглянуть на теорию и практику воспитательной работы, в том числе на используемые в ней приемы.

Если придерживаться аналогии, что коррупция - болезнь, то педагогическимо задачами становится своевременное выявление этой патологии сознания и профилактика "болезни" у тех, кто ей пока не подвержен, а также коррекция и обеспечение последующего выздоровления "заболевших". "Врач" должен действовать таким образом, чтобы вызвать у "пациентов" реакцию отторжения к коррупции, помочь им выработать антикоррупционный иммунитет.

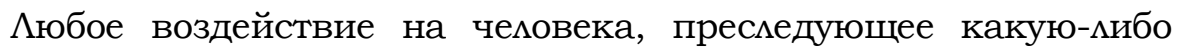
цель, является манипуляцией им. Отношение же к применению манипулятивных приемов среди педагогов отнюдь не однозначное. Некоторые считают, что манипуляция - аморальный способ достичь желаемого, так как это "обман", "принуждение" человека к принятию обычно невыгодного дмя него решения. Оксфордский словарь, например, определяет манипуляцию как скрытую обработку сознания, как акт влияния на Аюдей или управмения ими или вещами с мовкостью и особенно пренебрежительным подтекстом. Негативное отношение к манипуляции как психолого-педагогическому средству воздействия на человека может также являться результатом того, что в 60-е гг. XX столетия сложилось мнение о ней как о способе воздействия на сознание масс, "способе господства и вцасти" государства над обществом [4, с. 60]. То есть, с точки зрения, распространенной среди политологов, манипуляция служит средством "промывания мозгов" и программирования сознания и поведения населения. Приведем высказывание на этот счет С. Г. Кара-Мурзы: «Манипуляция - это способ господства путем духовного воздействия на Аюдей через программирование их поведения. Это воздействие направлено на психические структуры человека, осуществляется скрытно и ставит своей задачей изменение мнений, побуждений и цемей мюдей в нужном власти направлении" [4, c. 77].

Кроме того, отношение к человеку как объекту воздействия, стремление сделать его "марионеткой", утаивание действительной сущности осуществляемых действий, считается неприемлемым с позиций этики. Как отмечал Г. Шимлер, "для достижения успеха 
манипуляция должна оставаться незаметной». И далее: "Успех манипуляции гарантирован, когда манипулируемый верит, что все происходящее естественно и неизбежно. Короче говоря, дия манипуляции требуется фальшивая действительность, в которой ее присутствие не будет ощущаться" [7, с. 120].

В манипулятивном процессе собеседник воспринимается не как целостная уникальная мичность, а как носитель определенных, "нужных" манипулятору свойств и качеств, которые впоследствии будут использованы для достижения цели инициатора манипуляции. Манипулятор дия достижения запланированного результата не только использует уже существующие особенности человека, но также стремится создать новые - более удобные, мегко доступные или более эффективные "мишени". Подготовительные действия манипулятора могут быть и неманипулятивными, но иметь перспективу посмедующего использования с манипулятивными целями [1, с. 128].

Тем не менее психологи активно применяют приемы манипумяции в своей деятельности для решения проблем своих клиентов. Более того, в обыденной жизни каждый порой вынужден выступать в роли манипулятора или манипулируемого. То, что делает, например, психотерапевт, он демает фактически по просьбе пациента, выступая при этом манипулятором, программируя его мыс$\Lambda и$, установки, поведение, скрыто принуждая его к опредеменным действиям. Однако при этом все приемы и методы врача должны соответствовать этическим принципам, в противном случае (в обход желания адресата и при стремлении извцечь для себя выгоду) манипулирование граничит не только с нарушением моральных, но и в некоторых случаях правовых норм.

В целом манипуляция - вид психологического воздействия, мастерское выполнение которого ведет к скрытому возбуждению у другого человека намерений, не совпадающих с его актуально существующими желаниями и представлениями. В манипулятивном акте обязательно содержится знание о том, какая реакция должна последовать на предъявленный стимул. И чем точнее это знание, тем эффективнее будет манипуляция. Манипуляция не формирует реакций, а деформирует (просим прощения за тавтологию) уже сформированные.

Разновидностью манипуляции иногда называют провокацию - еще один из довольно интересных приемов искусственного возбуждения сознания и мыслительных процессов. Г. В. Грачев 
и И. К. Мельник рассматривают ее как вариант приемов информационно-психологического воздействия, относящихся к технологиям тайного принуждения мичности. На первый взгляд, может показаться, что отмичий между провокацией и манипумяцией, действительно, нет (кроме разве что тактических) - обе призваны оказывать влияние на человека, использовать его в основном в своих (а иногда в корпоративных), нередко корыстных целях.

Конечно, провокация, как и большинство манипуляций, явмяется жестким приемом, но не тождественна последним. Провокацию часто определяют как акцию вызывания гнева, умышленный вызов, подстрекательство; общественное сознание связывает ее с конфликтом, столкновением, противостоянием, нападением, скандалом, обманом, насилием, шоком и т. п. Вместе с тем она может включать в себя и побуждение, приглашение, взывание, соблазнение, стимулирование и мотивирование, дающие толчок к развитию мичности, к изменению установок, убеждений и проч.

Провокация как вызов обществу использовались еще в период Средневековья. Например, в то время юродивые, скоморохи, шуты пытались, и зачастую не без успеха, пробудить мнение общественности, вызвать ее реакцию на происходящие события намеренным фиглярством, суррогатами профанаций, изобличая и высмеивая при этом пороки, грехи и интерпретируя определенным образом негативные общественно значимые события. Таким образом юродивые выполняли функцию общественной терапии [3, с. 32]. Иными словами, провокативные действия (приемы провокации), которые сначала, при поверхностном взгяяде могут показаться антисоциальными, нарушающими нормы приличия, могут играть роль катамизирующего фактора для ряда изменений, причем не только негативных, но и положительных, и при правильном их направлении и использовании способны стать стимулом развития и отдельной мичности, и всего общества в целом.

Американский психотерапевт Фрэнк Фаремли создал и попуцяризировал уникальное направцение - провокативную терапию метод, разрушающий и расширяющий традиционные представмения о гуманистической психотерапии и использующий провокацию как способ активации ресурсов клиента. Ученый доказал, что невротику можно прямо говорить, что он невротик, а больному что он никогда не вылечится. Основа его метода - считать пациен- 
та человеком, а не "безвольной глистой в скафандре комплексов и маний». И пациент - о чудо! - перестает ею быть. И начинает думать, работать и выздоравливать.

Провокативная система Ф. Фаремии основана на том, что подопечного надо на время "вывести из равновесия" с помощью специально построенной психотерапевтической провокации, которая способна вскрыть и канализировать "внутренний гнойник", т. е. иррациональные установки и суждения клиента; затем предпринять меры, чтобы он не смог вернуться в исходное болезненное состояние. Фаремли, обладатель большого чувства юмора, использовал такие формы провоцирования больных, как преувеличение, передразнивание, высмеивание, доведение до абсурда, вербальная конфронтация, "негативное моделирование", "противоречивые сообщения" и т. д. [5].

Система Ф. Фаремли, на наш взгляд и по мнению некоторых специалистов сферы образования, может быть спроецирована на педагогику и практику воспитательной работы.

Так, А. В. Енин провокативную педагогику выделяет как часть педагогики воспитания и считает ее средством преодоления психических деприваций, с которыми традиционная педагогика справиться не может. Согласно А. В. Енину, одна из типичных педагогических ошибок - попытка воспитывать детей исключительно на позитивных примерах и социально одобряемых действиях. Такая практика ориентирует ребенка на подражание неким положительным образцам. Однако, кроме положительных черт, у каждого существуют и отрицательные качества, вызывающие соответствующие желания и стимулирующие к определенному поведению. Их нельзя скорректировать или вовсе устранить только запретами и нравоучениями. Здесь и может оказать помощь провокативная педагогика, в основе которой межит вызов воспитаннику, провоцирующий обратную реакцию мичности на преодоление отрицательного педагогического воздействия, в итоге активизирующий и усиливающий с помощью высвобождения скрытой энергии сопротивления позитивные ресурсы его "самости": самореализации, самоопредемения, саморазвития и др. [2, с. 2].

Работа педагога с воспитанником (как и психотерапевта с пациентом у Ф. Фарелци) включает в себя несколько этапов:

- провокация на вербальную коммуникацию (Ф. ФарелАи отмечал: «Задача - спровоцировать спонтанную реакцию клиента 
и “вскрыть" законсервированный набор его реакций... нужно нарушить его молчание и использовать всяческие стимулы, чтобы заставить открыто реагировать..." [5, с. 46]);

- установцение противоречий в вербальных реакциях и действиях;

- совместный поиск иррациональных (в нашем случае - коррупционных) суждений и установок;

- избавление от иррациональных суждений и проба новых реакций;

- самоутверждение воспитанника и интеграция его реакций в одно целое.

А. В. Енин считает центральным звеном в провокативной педагогике юмор (высмеивание, передразнивание, искажение, иронию, шутку, преувеличение), который позволит обратить потенциал "отрицательных" желаний и интересов в "позитив"; а наиболее приемлемыми формами "расшатывания" негативных мичностных стереотипов - ролевые Аибо имитационные игры, которым присущи наглядность и отсутствие назидательности. Ученый предупреждает и об ограничениях в применении методов провокативной педагогики: “... это обоюдоострый инструмент. Неграмотное обращение с ним может привести к прямо противоположному эффекту. Поэтому использовать эти методы можно только тем учителям, кто знаком с основами психологии и обладает навыками применения игровых методик. При этом педагогу следует руководствоваться принципом открытости в общении с ребятами, а также принципом “педагогического участия". То есть педагог должен сам участвовать в играх, задавая опредеменный “стиль” выхода за границы привычных норм" [2, с. 7].

Разыгрывая какую-либо ситуацию, педагог делает сам и предцагает сдемать детям нечто такое, что выходит за границы "обычных" представлений о правильном и неправильном, допустимом и запретном. То есть воспитанникам разрешается то, что вроде бы не должно поощряться взрослыми. Стандартные нормы и границы как бы сдвигаются, и каждому ребенку предоставцяется возможность самому решить, как далеко ему стоит зайти в следовании новым "антипедагогическим" установкам и принципам. Педагог искушает своих подопечных, вынуждая продолжить его неправомерные действия, которые внешне кажутся вполне цогичным про- 
должением предложенной ситуации. "Как правило, проживание такого “негативного опыта" вызывает у детей обратную реакцию: желание поступать вопреки “отрицательным" предписаниям взросмых. На этом эффекте, собственно, и строится расчет в провокативной педагогике. Согласитесь, одно демо, когда моральные нормы поведения вводятся взрослыми, и совсем другое, когда дети приходят к ним сами. В последнем случае идеальные положительные черты перестают восприниматься ребенком как навязанные извне; появляется осознание их необходимости, а сам человек начинает ощущать реальную свободу и ответственность" [2, с. 9].

В ходе игры нужно постоянно исподволь демонстрировать

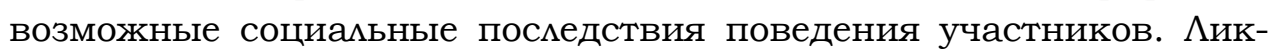
видация "гнойника" основывается на доказательстве иррациональности ошибочных убеждений воспитанников.

Прибегая, например, к приему гиперболизации, изображая явление (коррупцию) "больше и ярче», чем в жизни (для чего могут быть использованы самые невообразимые данные из мюбых источников), педагог сначала домжен определить степень коррупционных установок ребят и уровень привязанности к таким установкам. Заставить детей высказаться, обнаружить свою позицию может демонстрация отношения к избранной ситуации как к вполне рациональной. Затем, нарочито преувеличивая, утрируя некоторые обстоятельства совершения коррупционных актов или вероятные последствия коррупции, изображая их карикатурно и постепенно доведя до абсурда, показав "правдоподобный" конец, необходимо спровоцировать жемание подопечных оспаривать свои же суждения, помогая тем самым "выровнять" им внутреннюю шкалу ценностей, изменить оценку тех или иных обстоятельств.

Увидеть себя со стороны позволяет передразнивание - мимикрия. Задача педагога- изображая коррупционера, вызвать смех, иронию над теми, кто склонен к незаконному стяжательству, над их постоянным поиском и изобретением способов получать криминальные доходы, их страхом перед наказанием. Приемы клоунады

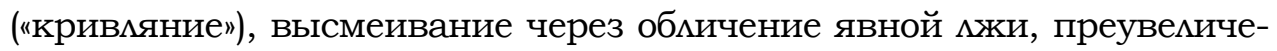
ние манеры поведения, копирование мимики миц, склонных к коррупции и взяточничеству, позволят обнаружить заблуждения некоторых воспитанников и вызвать у них реакцию отторжения прежних установок - мало кому нравится быть объектом всеобщих насмешек. 
Техника искажения (например, при разыгрывании ситуации кардинального изменения отношения медицинского персонала к больному в муниципальной поликлинике до и после обычного небольшого презента) применяется с целью прояснения мысли человека. Педагог может попросить воспитанника прокомментировать ситуацию, потом повторить комментарий с уточнениями мотивации ее персонажей и более упрощенным объяснением их поведения. Обычно при таком повторе ребенок выходит из привычного своего состояния, начинает путаться в знакомых понятиях, опредемениях, действиях, что с большой долей вероятности способствует переоценке предыдущего опыта, а иногда и открытию (часто неожиданному) внутри себя наличия антисоциальных установок.

Обосновывая иррациональность проблемных установок и суждений, педагог может использовать всяческие уловки: намеренные запутывание или отрицание, театральность, даже слезы. Гцавное, чтобы у ребенка поменялось отношение к определенным вещам и он начал понимать, что некоторые качества, которые он раньше считал отрицательными, не стоит оценивать так однозначно.

Самое важное в применении провокативных методик при антикоррупционном воспитании - не проявить невольно или сознательно неуважения к мичности, так как в этом случае человек может замкнуться в себе и цель педагогом не будет достигнута. Подопечные должны если не доверять педагогу, то хотя бы ощущать, что последний сопереживает вместе с ними (обратимся опять к Ф. Фаремии, который подчеркивал: "Самое главное, чтобы у клиента сформировалось чувство - что терапевт "на его стороне”" [5, с. 46]). Следует помнить также, что "некоторые дети чувствуют себя крайне некомфортно в условиях провокативного воздействия. Поэтому участие в такого рода играх должно быть делом сугубо добровольным - только по желанию ребенка" [2, с. 11].

Перенос провокативных приемов в воспитательные процессы педагогического взаимодействия обучающего и обучаемого представляется нам заслуживающим научного обсуждения и дамьнейшей разработки, а при решении задачи формирования антикоррупционного общественного и индивидуального сознания такая проекция достойна всяческой поддержки. 
Провокативные приемы при формировании антикоррупиионного сознания

\section{Аитература}

1. Доценко Е. $\Lambda$. Психология манипуляции: феномены, механизмы и защита. М.: ЧеРо: Изд-во МГУ, 1997.

2. Енин А. В. «Вредные игры»: плюс и минус // Психология учителю. 2010. № 3 (24).

3. Зонтаг С. Мысль как страсть: избр. эссе. М.: Русское феноменологическое общество, 1997.

4. Кара-Мурза С. Г. Манипуляция сознанием. М.: А^горитм, 2004.

5. Фаремли Ф., Брандсма Дж. Провокативная терапия. Екатеринбург: Е-Принт, 2012.

6. Юридическая психомогия. Понятие о мичности преступника: хрестоматия / сост. Б. Д. Аысков, Т. Н. Курбатова. СПб., 2001.

7. Шимлер Г. Манипуляторы сознанием. М.: Мысль, 1980. 